\title{
PERSPECTIVAS DO CROSS-CULTURE PARA AS BIBLIOTECAS HÍBRIDAS
}

Rafaela Carolina Silva

Rosangela Formentini Caldas

\begin{abstract}
Doutoranda em Ciência da Informação na Universidade Estadual Paulista "Julio de Mesquita Filho" - Campus de Marília. Mestre em Ciência da Informação pela Universidade Estadual Paulista "Julio de Mesquita Filho" - Campus de Marília. Especialista em Psicopedagogia Institucional pela Fundação para o Desenvolvimento do Ensino, Pesquisa e Extensão (FUNDEPE) Campus de Marília. Bacharel em Biblioteconomia pela Universidade Estadual Paulista "Julio de Mesquita Filho" Campus de Marília. Técnica em Secretariado pela ETEC Antônio Devisate - Unidade de Marília. E-mail: rafaela.c.silva@unesp.br; rafaelacarolinasilva@gmail.com
\end{abstract}

\begin{abstract}
Docente no Departamento de Ciência da Informação na Universidade Estadual Paulista "Julio de Mesquita Filho" - Campus de Marília. Doutora em Tecnologias e Sistemas de Informação pela Universidade do Minho, Portugal. Mestre em Ciência da Informação pela Pontifícia Universidade Católica, Campus de Campinas. Especialista em Controle Estatístico da Qualidade pela Universidade Estadual de Campinas, Campus de Campinas. Bacharela em Ciências Administrativas pela Universidade Estadual de Campinas, Campus de Campinas.Bacharela em Ciências Econômicas pela Universidade Estadual de Campinas, Campus de Campinas. E-mail: r.caldas@unesp.br
\end{abstract}

r.caldas

\section{RESUMO}

Nos costumes, histórias, leis, hábitos e comportamentos cotidianos, existe o modo de como as bibliotecas irão interagir com seus usuários. A maneira pelas quais uma biblioteca cria, organiza e dissemina a informação se transformam de acordo com as mudanças culturais vivenciadas. Assim, as Tecnologias de Informação e Comunicação vêm agregar valor às tecnologias analógicas de tratamento da informação para as bibliotecas híbridas, tornando-se necessário o entendimento acerca da cultura institucional para uma melhor atuação de tais instituições em suas comunidades. Nesse cenário, o método Cross-Culture destaca-se como uma metodologia de pesquisa que permite o entendimento das diferentes realidades das bibliotecas híbridas, a partir do reconhecimento da interculturalidade existente nesses ambientes. O objetivo do estudo compreendeu verificar o método Cross-Culture como uma metodologia passível de caracterizar os elementos que fundamentam o conceito de bibliotecas híbridas. A pesquisa caracterizou-se por ser de natureza qualitativa e exploratória. O método escolhido 
foi a Pesquisa Bibliográfica, utilizando-se das bases BRAPCI e SciELO pois correspondem a área da Ciência da Informação no âmbito internacional. O levantamento dos artigos deu-se por meio das palavras-chave "bibliotecas híbridas", "hibridez em bibliotecas", "conceito de bibliotecas híbridas" e "desenvolvimento cultural". Como resultados, observou-se que o método CrossCulture permite a visualização da hibridez em bibliotecas como ação indispensável para a promoção do acesso e atendimento às necessidades do público com quem atuam, uma vez que abarcam a convergência de informações, ferramentas, serviços e processos para que suas comunidades se desenvolvam. As bibliotecas híbridas podem ser conceituadas como equipamentos culturais que abrangem não somente políticas institucionais, mas a interligação destas com as políticas públicas que regem a cultura do seu público-alvo. Assim, ao se trabalhar com as políticas públicas inerentes a cada cultura, percebeu-se que o conceito de bibliotecas híbridas traz uma proposta de interculturalidade dentro dos equipamentos culturais. Nessa perspectiva, a biblioteca híbrida possui princípios institucionais flexíveis, que se moldam de acordo com o enfoque de cada localidade.

PALAVRAS-CHAVE: Hibridez em Bibliotecas. Conceito de Bibliotecas Híbridas. Método de Pesquisa Cross-Culture. Ciência da Informação. Desenvolvimento Cultural.

\title{
CROSS-CULTURE PERSPECTIVES FOR HYBRID LIBRARIES
}

\begin{abstract}
In the customs, stories, laws, habits, and behaviors in society, there is a way libraries will interact with their users. The way in which a library creates, organizes and disseminates information is transformed according to the cultural changes experienced. In this way, Information and Communication Technologies add value to the analog technologies of information processing for hybrid libraries, making it necessary to understand the institutional culture for a better performance of such institutions in their communities. In this scenario, the Cross-Culture method stands out as a research methodology that allows the understanding of the different realities of the hybrid libraries, from the recognition of the interculturality existing in these environments. The objective of the study was to verify the Cross-Culture method as a methodology that characterizes the elements that underlie the concept of hybrid libraries. The research was characterized by a qualitative and exploratory nature. The method chosen was Bibliographic Research, using the databases BRAPCI and SciELO as they correspond to the area of Information Science in the international scope. The articles were surveyed using the keywords "hybrid libraries", "library hybridity", "hybrid library concept" and "cultural development". As results, it was observed that the Cross-Culture method allows the visualization of hybridization in libraries as an indispensable action to promote access and attend to the needs of the public with whom they work, since they cover the convergence of information, tools, services and processes for their communities to develop. Hybrid libraries can be conceptualized as cultural equipment that encompasses not only institutional policies, but also the interconnection of these with the public policies that govern the culture of its target audience. It concludes that, when working with the public policies inherent to each culture, it was perceived that the concept of hybrid libraries brings a proposal of
\end{abstract}


interculturality within cultural equipment. From this perspective, the hybrid library has flexible institutional principles, which are shaped according to the focus of each locality.

KEYWORDS: Hybridity in Libraries. Concept of Hybrid Libraries. Cross-Culture Research Method. Information Science. Cultural Development.

\section{INTRODUÇÃO}

A relação existente entre as culturas de cada sociedade projeta-se como fator de entendimento de um povo. Assim, a capacidade de observar as divergências e as similaridades culturais pode trazer benefícios às comunidades e gerar desenvolvimentos significativos, já que, ao abranger as diferenças culturais, as bibliotecas, enquanto promotoras de conhecimento, podem se apropriar diferentemente no compartilhamento da informação. Entende-se, portanto, que as maneiras pelas quais uma biblioteca cria, organiza e dissemina a informação se transformam de acordo com as mudanças culturais de seus usuários.

Nesse contexto, as Tecnologias de Informação e Comunicação (TIC) vêm agregar valor às tecnologias analógicas de tratamento da informação, dando início às discussões acerca do conceito de bibliotecas híbridas. Tal conceito trabalha com a convergência de tecnologias analógicas e digitais para melhor lidar com as mudanças em sociedade e as novas perspectivas que essas mudanças trazem às bibliotecas.

Logo, torna-se necessário um entendimento acerca da cultura institucional para uma melhor atuação nas bibliotecas - suas normas, valores e regras, assim como uma discussão acerca da teoria de hibridez e sua aplicação nas diferentes localidades onde existam bibliotecas denominadas híbridas, já que essas bibliotecas também poderiam atuar em outras áreas de suas comunidades. Nesse cenário, o método Cross-Culture destaca-se como uma metodologia de pesquisa que permite o entendimento das diferentes realidades das bibliotecas híbridas, a partir do reconhecimento da interculturalidade existente nesses ambientes.

O objetivo do estudo compreendeu verificar se o método Cross-Culture poderia se designar como uma metodologia passível de caracterizar os elementos que fundamentam o conceito de bibliotecas híbridas. Buscou-se um conceito que destacasse as bibliotecas híbridas como parte de um cenário de auxílio em suas comunidades.

A abordagem do estudo foi de natureza qualitativa, do tipo descritiva e exploratória. Utilizou-se do método Pesquisa Bibliográfica, a partir do uso dos descritores "bibliotecas híbridas", "hibridez em bibliotecas", "conceito de bibliotecas híbridas" e "desenvolvimento cultural" como assuntos principais e títulos em bases de dados nacionais e internacionais da 
área da Ciência da Informação.

\section{BIBLIOTECAS HÍBRIDAS}

As bibliotecas híbridas partem "[...] de uma visão extensionista do conceito de bibliotecas, nas quais, por meio do conhecimento construído, exige-se o exercício da cidadania" (SILVA et al., 2018, p. 406), buscando “[...] identificar pequenos grupos de usuários e oferecer serviços mais especializados de valor agregado, com grande flexibilidade e criatividade em sua realização e forma, por meio do diagnóstico do que o usuário deseja, realizado de uma forma continuada" (GARCEZ; RADOS, 2002, p. 46). Dessa maneira, a estrutura da biblioteca híbrida "[...] entrelaça todos os conceitos em um único pensamento, e cria uma nova versão de biblioteca, que se utiliza das tecnologias e usufrui de um acervo digital, mas também mantém o formato tradicional ao disponibilizar um acervo físico" (CAVALCANTE; BRITO; VLAXIO, 2016, p. 48).

Ao passo que esses ambientes requerem um ceticismo quando entendendo que nem tudo o que está em meio tradicional perde seu valor, e que nem tudo que está em meio digital é necessário, induzem a uma visão subjetiva quando em tratando dos sujeitos que interagem com a instituição, a fim de entender suas motivações e necessidades informacionais. Sendo assim, ao se trabalhar com as bibliotecas híbridas é preciso levar em conta sua arquitetura, serviços e produtos oferecidos, relações sociais, design da informação, convergência de linguagens, aprender a aprender ao longo da vida, melhoria futura, funcionários, usuários, coleção, design interno, design externo, gerenciamento local da informação e gerenciamento externo da informação.

Para Silva, Jorente e Caldas (2017, p. 278), nas bibliotecas híbridas existe “[...] uma maior dialogicidade dos produtos e serviços, uma vez que há uma convergência de mídias tecnológicas e de linguagens". Nesse contexto, os processos tradicionais desempenhados pela biblioteca tradicional passam a contar com diversos tipos e formatos de tecnologias informacionais, sendo esses uma complementação das mídias digitais às mídias tradicionais.

Silva e Caldas (2017, p. 7, tradução nossa) entendem que, para além da convergência de tecnologias, a biblioteca híbrida deve "ser um espaço cultural, que favoreça a promoção de diálogos, onde indivíduos e tecnologias interagem, a fim de que a informação preservada na biblioteca ganhe vida à medida em que são úteis aos usuários e, portanto, usadas”. Logo, o ambiente dessas bibliotecas é interativo e estimulante, passível de construir uma relação de 
multiculturalismo de dados, informação e conhecimento, estando o conceito de hibridez presente na promoção da informação.

\section{MÉTODO DE PESQUISA CROSS-CULTURE}

A pesquisa Cross-Culture nasceu da área da Antropologia do final do século XIX, como uma metodologia de teor estatístico, compilando-se, posteriormente, com a etnografia. Entre os anos de 1930 e 1940, o método foi bastante utilizado para entender as relações humanas em bibliotecas.

Em meados da década de 1990, começou a ser aplicada, por Richard Lewis ${ }^{1}$, como um modelo não somente estatístico, mas também capaz de entender o comportamento dos seres humanos em seus diferentes contextos. A Figura 1 mostra a trajetória do pensamento da pesquisa Cross-Culture:

Figura 1 - Linha do tempo da pesquisa Cross-Culture.

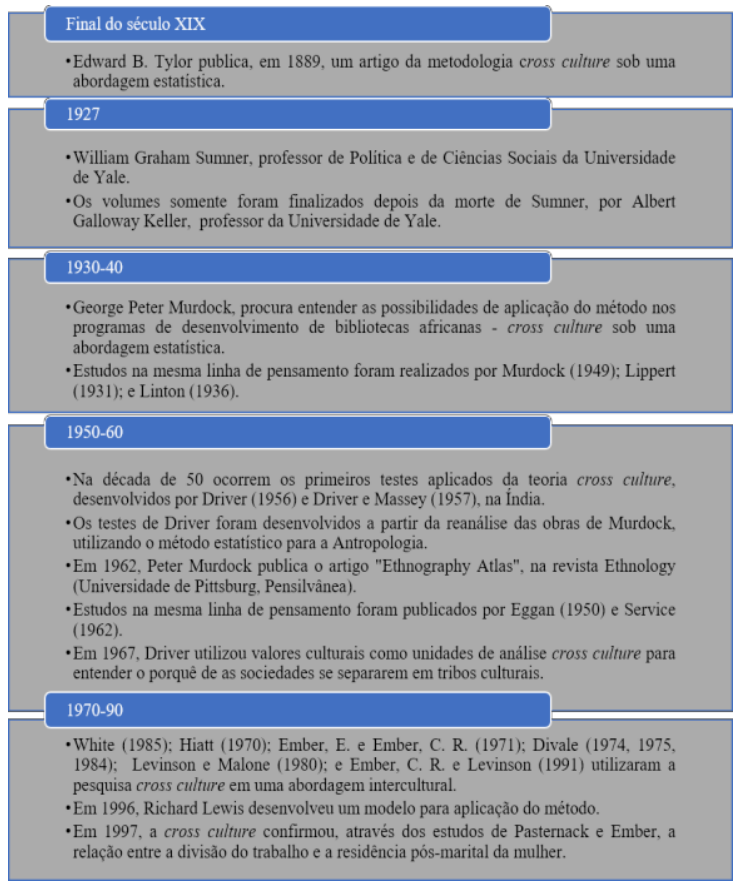

Fonte: Elaborada pelas autoras.

O modelo de pesquisa comparativa Cross-Culture de Lewis (1996) leva em conta que os seres humanos podem ser divididos em três categorias, baseadas em seu comportamento, que variam de acordo com sua localidade. A saber: 1) Grupo Linear-Ativo: Compreende o mundo da língua inglesa - América do Norte, Grã-Bretanha, Austrália, Nova Zelândia e Europa do Norte, incluindo a Escandinávia e os países germânicos; 2) Grupo Reativo: Localizado nos principais países da Ásia, exceto o subcontinente indiano, que é híbrido; 3) Grupo Multi-Ativo: 
Espalhados pelo Sul da Europa, países Mediterrâneos, América do Sul, África Subsaariana, árabes, Índia e outros países do Oriente Médio, como Paquistão e eslavos.

Ao passo em que essas culturas são diversas, geograficamente, e em suas religiões, crenças e valores, elas podem ser categorizadas como um grupo, já que, em nível comportamental, seguem o mesmo padrão de vida no que se refere às seguintes características:

a) demonstração de emoção, b) uso de retórica, c) capacidade de persuasão, d) expressiva linguagem corporal, e) importância da religião ou credo, f) primazia dos laços familiares, g) ética de trabalho, h) volatilidade, i) capacidade de planejamento, j) capacidade de compaixão, k) coletivismo, l) desenvolvimento de relacionamentos e m) sociabilidade (LEWIS, 1996), sendo possível observar alguns elementos comportamentais semelhantes. Nessa perspectiva, a pesquisa intercultural aparece nas comparações entre conceitos culturais, criação de organizações e a posterior geração de filiais, comparando, ao mesmo tempo, diferentes sociedades, incluindo culturas, ambientes e instituições, com dados interculturais de interpretação (ILESANMI, 2009).

Entende-se que a Cross-Culture é a tipologia de pesquisa comparativa que valida o estudo de casos múltiplos, na medida em que prima pela especificidade de cada aspecto determinante das diferentes regiões. Logo, a interatividade e a conectividade das diversas sociedades requerem novas competências e habilidades nos processos de acesso, seleção, articulação, organização e apreensão da informação, com vistas a uma abordagem interdisciplinar.

A pesquisa comparativa Cross-Culture seleciona, por meio de múltiplas estratégias, características e metodologias de trabalho encontradas nos locais, a fim de torná-las compreensíveis às diferenças culturais dos contextos estudados. Ressalta-se, pois, que a utilização de conceitos se difere de acordo com cada cultura, como é o caso do conceito de bibliotecas híbridas.

Para tanto, são consideradas características da diversidade cultural e do multiculturalismo, que coexistem na interação entre culturas. A cultura, nesse método, deve ser considerada como o conjunto de distintivos cognitivos, intelectuais e emocionais (do ser humano) e materiais (recursos documentais) da sociedade ou do grupo social que abrange, para além da arte e da literatura, dos estilos de vida, das formas de convivência, dos sistemas de valores, das tradições e das crenças (INTERNATIONAL..., 2001). 


\section{METODOLOGIA}

A abordagem do estudo foi de natureza qualitativa, do tipo exploratória. O método de pesquisa utilizado foi a Pesquisa Bibliográfica na Base de Dados Referenciais de Artigos e Periódicos em Ciência da Informação (BRAPCI) e na Scientific Electronic Library Online (SciELO).

A tipologia exploratória, neste estudo, consistiu em aprofundar e sintetizar aspectos conceituais obtidos do referencial bibliográfico, vinculados ao objeto de estudo. Já a tipologia descritiva, em entender as diversas relações que ocorrem nos contextos social, político e econômico dos diferentes contextos dos equipamentos culturais.

Levando em conta que a pesquisa bibliográfica objetiva desvendar e analisar informações e conhecimentos prévios sobre um determinado fato e/ou assunto (MACEDO, 1994), neste estudo, ela foi utilizada para levantar os artigos disponíveis nas bases de dados nacionais e internacionais especializadas na área da Ciência da Informação. O levantamento dos artigos estudados ocorreu por meio das palavras-chave "bibliotecas híbridas", "hibridez em bibliotecas", "conceito de bibliotecas híbridas" e "desenvolvimento cultural", como assuntos principais e títulos.

Importante destacar que não houve delimitação de tempo, já que o intuito era recuperar o maior número de literatura possível sobre o assunto. $\mathrm{O}$ foco da coleta de dados foram os resumos dos artigos científicos levantados e a escolha pelas bases de dados ocorreu pelo fato de elas representarem a integração de todas as áreas da Ciência da Informação e da Biblioteconomia em âmbito nacional e internacional.

\section{RESULTADOS E DISCUSSÕES}

Como arcabouço teórico, observou-se que a pesquisa Cross-Culture objetiva estudar as culturas, delimitando suas características específicas, a fim de entender como as mesmas podem ser aplicadas em uma cultura totalmente diferenciada das estudadas. É preciso, assim, ressaltar as similaridades e as diferenças de cada cultura, para que haja um diálogo entre os aspectos específicos de cada contexto e, a partir disso, uma aplicação desses dados em cenários diversificados.

A análise da literatura permitiu entender que o conceito de bibliotecas híbridas é constituído por quatro fatores: 1) o indivíduo, 2) os produtos e serviços oferecidos, 3) o ambiente interno e 4) a tecnologia. Dessa maneira, as bibliotecas híbridas trabalham com os 
funcionários por meio de 1) workshops para identificar e trabalhar suas dúvidas, 2) análises das barreiras no desenvolvimento de suas habilidades, 3) identificação das necessidades de aprendizagem, 4) avaliação do potencial desses indivíduos, 5) desenvolvimento pessoal e treinamento, 6) desenvolvimento de carreira, 7) educação continuada e 8) trabalho voluntário. Já os usuários são enfatizados através 1) da aprendizagem à distância, 2) das necessidades de mudanças nas bibliotecas, 3) do treinamento de usuários, 4) do estudo de usuários, 6) da aprendizagem ao longo da vida, 7) da cidadania digital e 8) do envolvimento das comunidades de usuários nas atividades desenvolvidas pelas bibliotecas.

A prestação de serviços, em parceria com outras bibliotecas ou centros educacionais, é um item sempre presente quando se fala em bibliotecas híbridas, corroborando para com as ações culturais, educacionais e de acolhimento das comunidades de seu entorno. Alguns dos serviços presentes nas bibliotecas híbridas são 1) auto empréstimo; 2) acessibilidade; 3) pesquisa a bancos de dados; 4) acesso à internet; 5) cursos; 6) oficinas; 6) treinamento de usuários; 7) treinamento de funcionários; 8) assistência social; 9) programas permanentes; 10) oficinas; e 11) eventos. Sendo assim, as vantagens dos serviços e produtos prestados pelas bibliotecas híbridas está 1) no acesso fácil e rápido à informação; 2) na disponibilização da informação via internet; 3) na maior autonomia do usuário; 4) na possibilidade de cobertura internacional, nacional, regional e local; 5) na parceria com outros centros educativos, como arquivos e museus para a disponibilização do acervo; 6) no trabalho voltado aos diferentes perfis de usuários e na adequação de seus produtos às necessidades e expectativas dos mesmos; 7) na flexibilização de operações; e 8) na prestação de serviços em tempo hábil.

No que se refere à estrutura e ambientação das bibliotecas híbridas, a hibridez ocorre por meio: (1) de práticas internacionais; (2) da sintonia com as ações governamentais; (3) dos espaços arrojados, possuindo projeto inovador de inclusão social por meio da leitura (a estrutura dessas instituições foi planejada para oferecer conforto, autonomia e atenção aos frequentadores, que são o elemento central da biblioteca); (4) da revitalização dos prédios; (5) das informações disponíveis em variados tipos de suporte e mídias; (6) da ambientação, que oferece ao público um espaço acolhedor e aconchegante, como convite para a leitura; 7) da sociedade, que pode contribuir na escolha de itens a serem adquiridos para o acervo; e (8) dos acervos, atualizados frequentemente.

Logo, o conceito de bibliotecas híbridas se designa como um modelo de bibliotecas com foco no desenvolvimento social, abrangendo, em seu ambiente, a prática de profissionais da 
informação em prol de convergir 1) tecnologias, como ferramentas estratégicas no auxílio ao desenvolvimento de processos; 2) pessoas, buscando uma equipe de trabalho multidisciplinar, passível de entender os diferentes indivíduos que fazem parte da comunidade de usuários do local, bem como suas necessidades e desejos informacionais; 3) sistemas de interoperabilidade de dados, a fim de trocar informação entre instituições e, consequentemente, com a sociedade, buscando padrões de intercâmbio de informações, para que falhas na comunicação e incompatibilidades entre sistemas possam ser evitadas; e 4) o estudo organizacional, a fim de entender os recursos pertencentes à biblioteca, seu público, e quais recursos ainda são necessários adquirir.

\section{CONSIDERAÇÕES FINAIS}

Ao se cruzar as fronteiras culturais, tem-se uma diversidade de grupos, com diferentes estilos de vida, formas de convivência, sistemas de valores, tradições e crenças. Diante disso, entendendo a cultura como sinônimo de civilização, adaptada, imaginada e controlada pelo homem, os equipamentos culturais, como as bibliotecas híbridas, são resultado de cada um dos povos, nações, indivíduos e grupos humanos, bem como de suas variações.

Valendo-se de pesquisas comparativas, é possível entender os deslocamentos e as transformações de uma cultura, identificando suas semelhanças e diferenças. No entanto, para se cruzar fronteiras, é preciso ressaltar que uma cultura não pode ser adaptada, sem estudos próprios, a outra cultura.

Assim, preservando as particularidades de cada cultura, é possível que dois ou mais contextos totalmente diferentes possam ser trabalhados em conjunto, a fim de atingir um determinado objetivo. Diante disso, o método de pesquisa Cross-Culture, ainda pouco explorado pela área da Ciência da Informação, é um caminho que direciona o pesquisador ao entendimento da diversidade cultural em equipamentos culturais.

As bibliotecas híbridas, inicialmente tratadas apenas pelo âmbito da convergência de tecnologias, ao trabalharem com a comunicação e com a troca de informação entre pessoas, equipamentos culturais, sistemas de computador, dentre outros, destacam-se como instituições promoventes do desenvolvimento social dos indivíduos. Dito isso, a biblioteca híbrida trabalha com as mudanças ocorridas em sociedade para atender às necessidades e desejos informacionais dos seus usuários, em prol de não se estagnar no tempo.

Nesse sentido, as bibliotecas híbridas podem ser conceituadas como equipamentos 
culturais que abarcam não só políticas institucionais, mas, a interligação dessas políticas com as políticas públicas que regem a cultura do seu público-alvo. Assim, ao se trabalhar com as políticas públicas inerentes a cada cultura, percebeu-se que o conceito de bibliotecas híbridas traz uma proposta de interculturalidade dentro dos equipamentos culturais, possuindo princípios institucionais flexíveis, que se moldam de acordo com o enfoque dado por cada localidade trabalhada.

\section{REFERÊNCIAS BIBLIOGRÁFICAS}

SOUZA, Maria das Graças. Natureza e Ilustração: sobre o materialismo de Diderot. São Paulo: UNESP, 2002. CAVALCANTE, K. V.; BRITO, Y. R.; VLAXIO, F. As metamorfoses da biblioteca para a Geração Z: proposta de implementação para o Espaço Cultural Bezerra de Menezes. Revista Analisando em Ciência da Informação, v. 4, n. 2, p. A03, 2016. Disponível em: <http://www.brapci.inf.br/v/a/28284>. Acesso em: 18 jul. 2018.

GARCEZ, E. M. S.; RADOS, G. J.

V. Biblioteca híbrida: um novo enfoque no suporte à educação a distância. Ciência da Informação Brasília, v. 31, n. 2, 2002. Disponível em:

<http://www.scielo.br/scielo.php?pid=S $010019652002000200005 \&$ script $=$ sci_a bstract\&tlng=pt>. Acesso em: 14 jul. 2018.

ILESANMI, O. O. What is Crosscultural Research? International Journal of Psychological Studies, v. 1, n. 2, dez. 2009. Disponible at: $<$ http://www.ccsenet.org/journal/index. php/ijps/article/view/2212/3838>.

Access: 01 jan. 2018.

INTERNATIONAL FEDERATION OF LIBRARY ASSOCIATIONS AND

INSTITUTIONS. The multicultural library: a gateway to a cultural diverse society in dialogue. 2001. Disponível em:

$<$ http://www.ifla.org/files/assets/library- services-to-

multiculturalpopulations/publications/m ulticultural_library_manifesto-en.pdf > . Acesso em 24 mar. 2018.

LEWIS, R. D. The Lewis Model: dimensions of behavior. 1996. In: CROSSCULTURE. The Lewis Model. CrossCulture: Warnford, 2017. Disponível em: <http://www.crossculture.com/aboutus/the-model/>. Acesso em: 09 fev. 2018.

MACEDO, N. D. Iniciação à pesquisa bibliográfica: guia do estudante para a fundamentação do trabalho de pesquisa. 2. ed. São Paulo: Edições Layola, 1994.

SILVA, R. C. da; CALDAS, R. F. Las bibliotecas públicas híbridas en el contexto brasileño. Palabra Clave, v. 6 , n. 2, 2017. Disponível em: <http://eprints.rclis.org/31301/>. Acesso em: 11 jul. 2018.

SILVA, R. C. da; JORENTE, M. J. V.; CALDAS, R. N. F. Integração da competência em informação no contexto das bibliotecas vivas. Revista Ibero-Americana de Ciência da Informação, v. 10, n. 2, 2017. Disponível em: <http://www.brapci.inf.br/v/a/30301>. Acesso em: 18 jul. 2018.

SILVA, R. C. da; OTTONICAR, S. L. C.; CALDAS, R. F.; CASTRO FILHO, C. M. de. A competência em informação $e$ o comportamento informacional dos 
usuários de bibliotecas híbridas: um estudo comparativo no Brasil e na Escócia. Informação \& Informação, Londrina, v. 23, n. 1, p. 398-423, jan./abr. 2018. Disponível em:

<http://www.uel.br/revistas/uel/index.p hp/informacao/article/view/30906>. Acesso em: 15 jul. 2018.

SILVA, R. C.; CALDAS, R.F. Perspectivas do Cross-Culture para as Bibliotecas Híbridas. Complexitas - Rev. Fil. Tem. Belém, v. 3, n. 1, p. 89-99, jan./jun. 2018. Disponível em:< http://www.periodicos.ufpa.br/index.php/complexitas/article/view/6635>. Acesso em: 20 de fevereiro de 2019. 